\title{
Green with underappreciation
}

\begin{abstract}
"What do cells, genes, transposons, telomeres, RNA silencing and DNA recombination have in common? They were all discovered in plants." This is how Rob Martienssen emphasizes the contributions of plant research. We asked plant scientists whether their field is getting adequate support and proper recognition and heard a resounding "no."
\end{abstract}

A popular elementary school science project involves seeds and moist paper towel in a glass jar and monitoring germination. Watching those inert little things sprout roots and shoots mesmerizes children and adults alike: how does that happen? How can the seed be alive? Well, a body of research has shown that the plant hormone abscisic acid (ABA) controls seed dormancy and plant development, as well as environmental responses.

Unraveling ABA signaling has been challenging, but last year several high-profile papers, including an article in our pages (P. Yin et al. Nat. Struct. Mol. Biol. 16, 1230-1236, 2009), conclusively identified the ABA receptors and revealed the molecular mechanisms involved in signaling. These discoveries were highlighted by Science magazine as one of the breakthroughs of 2009. There are 14 members of this family, called PYRs (for "pyrabactin resistance"), PYLs (PYR-like proteins) or RCARs (for "regulatory component of ABA receptor"). PYR/PYL/RCAR proteins bind $\mathrm{ABA}$ and also interact with a phosphatase involved in $\mathrm{ABA}$ signaling. ABA binding then induces a conformational change in the receptor proteins, resulting in the recruitment and inactivation of the phosphatase.

Now two papers on pages 1102 and 1109 of this issue investigate the differences among the PYR/PYL/RCAR proteins revealing the structural bases for their responses to pyrabactin, a synthetic agonist for the ABA response in seeds. In both papers, the structural approach is accompanied by diverse functional analyses. The work has implications for selective agonists and antagonists design that could allow control of plant or crop growth and development, according to George Phillips, coauthor of one of the papers.

This fast-paced progress in understanding ABA signaling shows how far the plant field has moved. With all the tools now available, plant researchers are uncovering the molecular mechanisms responsible for processes at the cellular and organismal levels. We asked a few scientists in the field whether there is adequate funding to support these endeavors in basic plant research. Though funding woes currently exist in all fields, the response we got from plant researchers was particularly gloomy.

In the United States, the main sources of funding for plant research are the National Science Foundation (NSF) and the US Department of Agriculture (USDA). For 2010, the NSF intends to award about $\$ 20$ million to new grants through its Plant Genome Research Program. The USDA has recently launched the National Institute of Food and Agriculture (NIFA) to support public-sector agricultural science by, among other things, awarding NIH-like competitive grants. With a 2010 budget of over $\$ 1$ billion, NIFA could provide a welcome boost to academic plant research, but its first funding request was explicitly for work on crops, which, according to one plant scientist, "typically (but not always) make for not-so-good model systems."
Finally, there is the NIH, which has deeper pockets than these other agencies (a 2011 budget of $\$ 31$ billion) and does fund plant research. However, the plant scientists we talked to all feel their field is not properly recognized by the scientific community at large, creating a negative bias when it comes to funding. Structural biologist Ning Zheng is convinced that his grant proposals on plant systems have a tougher time than his other projects, an experience shared by Eric Xu. Plant biologist Sean Cutler finds that "the bar is set way higher" at NIH for basic research in plants, compared to other model organisms, such as worms, flies and yeast, even though work in plants is often just as relevant to fundamental mechanisms. Steve Jacobsen agrees that the field is underfunded "because people do not recognize the general utility of basic plant research." Jacobsen and other plant biologists have argued that Arabidopsis thaliana is a valuable model system that has already yielded insights into processes important to human health and disease. A similar point was made by David Baulcombe who stressed that, to attract the best students into plant science, it is essential that they know what good experimental systems plants can be.

Basic plant research also provides us with a fundamental understanding of plant-specific processes. Plants do lots of very important things: they photosynthesize and create most of the biomass that we eventually consume, as food, wood and fuel; they synthesize a plethora of chemical compounds with all kinds of potentially interesting activities. Thus, in addition to inherent intellectual interest, there are obvious biotechnological applications, too, for knowledge of basic plant biology.

Still, the impact of plant biology seems to fly under the radar of some scientists working in different fields. One researcher told us about NIH study section reviewers looking down on a particular proposal because "there are no human orthologs" for the proteins being investigated and hence the work had no significance (the work was eventually published in Nature). According to Rob Martienssen, "agriculture and biofuels will impact human health and the environment much more than curing cancer, for example, and it is hard to justify the 10-100-fold difference in funding." Furthermore, Zheng thinks that "from global warming and frequent natural disasters to food shortage and alternative energy, many areas beg for the immediate and effective application of biotechnology to plants."

On the bright side, major scientific journals, including NSMB, are perceived as appreciating plant research, an opinion shared by some of the scientists we consulted. In fact, besides the ABA papers, work on Arabidopsis is to be found in our pages. We recently featured an Essay by Jaillais and Chory (http://www.nature.com/nsmb/journal/ v17/n6/abs/nsmb0610-642.html) as part of our special Focus on Signal Integration. Thus, we hope the plant research community will always feel welcome at $N S M B$, whose editors remain utterly fascinated by those germinating seeds. 